\title{
The evolution of shelter 'self-recovery': adapting thinking and practice for post-disaster resilience
}

\author{
John Twigg ${ }^{\circ}$
}

Abstract: Providing adequate shelter after disasters is often a huge challenge to humanitarian agencies, whose interventions may reach only a small proportion of affected households. To overcome this problem, the international humanitarian shelter sector is increasingly adopting what is called a 'self-recovery' approach that gives much greater choice and agency to disaster-affected households regarding their recovery pathways. This article reviews the concept of 'self-recovery', its application to housing reconstruction after disasters and the factors influencing its recent rise to prominence in humanitarian policy and practice. The article draws on academic studies, evidence generated by humanitarian agencies and the author's involvement as observer and participant in recent self-recovery initiatives.

Keywords: disaster, humanitarian, shelter, recovery, reconstruction, agency.

Note on the author: Dr John Twigg is an independent researcher, an Honorary Professor at University College London, and a co-editor of the journal Disasters. He has worked in the field of disasters, risk and resilience for more than 20 years, in the academic, NGO and consultancy sectors. His recent publications include: Twigg, J. et al., Accountable Governance and Resilient Development: Thinking and Acting for Transformative Change (Oxfam International, 2020); Twigg, J. and Mosel, I., 'Emergent Groups and Spontaneous Volunteers in Urban Disaster Response' (Environment \& Urbanization, 29(2): 443-458, 2017); and Twigg, J., Disaster Risk Reduction (London: Humanitarian Practice Network, Good Practice Review no. 9, 2nd edition, 2015).

(C) The author(s) 2021. This is an open access article licensed under a

Creative Commons Attribution-NonCommercial-NoDerivs 4.0 Unported License 


\section{Introduction}

Building collapse is a major cause of injury, trauma and death in disasters. Between 2005 and 2018 more than 3.3 million houses were damaged and over 2.7 million destroyed globally by natural hazards and conflict. ${ }^{1}$ However, providing adequate shelter after disasters is 'one of the most intractable problems in international humanitarian response' ${ }^{2}$ and a repeated challenge to post-disaster response and recovery. Humanitarian agencies' interventions to repair and rebuild houses reach a relatively small proportion of those affected. ${ }^{3}$ Rebuilding a home is an immediate priority for disaster-affected households, but post-disaster assistance often takes time to arrive, and rebuilding destroyed and damaged housing can take many years. ${ }^{4}$

This article discusses the evolution of an approach commonly referred to as shelter 'self-recovery' that aims to support more rapid, effective and inclusive shelter reconstruction after disasters. The approach, which has gained considerable momentum in the past few years, has engaged researchers and humanitarian practitioners in an ongoing dialogue, seeking to understand what self-recovery is and how best to support it through policies and programmes. The aim of the article is to review and reflect upon the evolution of self-recovery: how the concept and practice have been developed and applied in the international humanitarian shelter sector, and the factors influencing this rise to prominence. Better understanding of these processes should assist humanitarian shelter practitioners, policy makers and donors to improve practice and target their support more effectively. I have drawn on academic writing on disasters and reconstruction, the numerous evaluations, reports and other data generated by humanitarian agencies on their shelter interventions, and my own views from involvement as an observer and participant in self-recovery initiatives since 2016.

\section{Humanitarian shelter intervention}

Shelter serves many functions before, during and following disasters. It provides a place to store belongings, protection against the elements (cold, heat, wind and rain), emotional security and privacy. It is a staging point for future action, including salvage and reconstruction, and an address for delivery of services such as food and medicine. It also demonstrates a territorial claim through ownership and occupancy rights. ${ }^{5}$

\footnotetext{
1 Sharma (2018).

2 Ashdown et al. (2011: 25).

${ }^{3}$ Parrack et al. (2014); Maynard et al. (2017); Miranda Morel (2018).

${ }^{4}$ Davis \& Alexander (2016).

${ }^{5}$ Davis et al. (2015).
} 
House-building in low-income countries and communities is often an informal process driven by householders and community groups. ${ }^{6}$ In development practice, it has long been understood that assisting organisations should support such processes rather than just providing houses. This involves identifying critical interventions regarding access to, and management of, land, services, finance and technical assistance. Humanitarian shelter policy and practice have been slower to adopt such supporting approaches or to acknowledge the incremental nature of the housing process, the multiplicity of shelter pathways taken by disaster-affected families and the importance of owner-driven approaches to housing reconstruction. ${ }^{7}$

Self-recovery can be seen as the latest stage in the evolution of thinking and practice about effective, appropriate shelter provision after disasters. It is an extension of much earlier ideas and approaches to development and disaster response (for example, community participation and owner-led reconstruction). Ian Davis' book Shelter after Disaster (1978) - the first serious critique of top-down, technocratic approaches to emergency shelter provision and reconstruction - argued against imposed and often impractical designs for rebuilding houses that were alien to their inhabitants' social, economic and cultural needs. He recognised that 'people build their homes in response to their everyday needs - their occupations, their wealth, their traditional construction techniques and their cultural patterns'; and he observed that house reconstruction 'usually starts immediately, and takes place irrespective of government plans for relocation etc'. Four years later, Davis and colleagues placed emphasis on shelter needs from the standpoint of the survivor receiving aid, pointing out that selfhelp and participation by local households, builders and craftsmen were key elements in reconstruction: 'The primary resource in the provision of post-disaster shelter is the grass-roots motivation of survivors, their friends and families.'

The basic contours of this discussion have remained similar in the decades since Shelter after Disaster was published. There has been consistent and widespread criticism of the persistence of 'donor-driven' housing reconstruction: supply-driven, agency approaches that build and deliver houses without listening to disaster-affected households' views or understanding their needs and priorities. This often leads to inappropriate designs, building materials and even locations. Counter-arguments have made a case for more developmental, 'people-centred' or 'owner-driven' reconstruction that responds to demand, on the grounds that most people build or manage their own house construction in any case, and because the participatory process is itself empowering. ${ }^{9}$

\footnotetext{
${ }^{6}$ Schilderman (2010).

7 Maynard et al. (2017).

${ }^{8}$ Davis (1978: 6, 30); Davis et al. (1982: 3).

${ }^{9}$ Davis and Alexander (2016).
} 
In particular, the experiences of the widespread destruction caused by the 2004 Indian Ocean tsunami in several Asian countries revealed the inadequacy of conventional, formal reconstruction approaches to meet housing needs, and stimulated greater uptake of more owner-driven, people-centred, participatory processes. The first of the 10 'Key Propositions for Building Back Better' set out by the UN Secretary General's Special Envoy for Disaster Recovery (former US President William J. Clinton) in his report on lessons learned from the tsunami was that 'Governments, donors, and aid agencies must recognize that families and communities drive their own recovery'. ${ }^{10}$

Yet in practice many reconstruction projects that are said to be 'owner-driven' continue to restrict owners' agency. Donors, humanitarian organisations and governments continue to direct building strategy and choose or develop designs, while householders are only involved in the act of construction. ${ }^{11}$ The principles that are widely repeated in formal guidance on shelter recovery and reconstruction, based on many years of lessons learned, often appear to have little influence on organisational practice. In addition, community participation in formal recovery initiatives can be a time- and resource-consuming process. For example, in Aceh, Indonesia, after the 2004 tsunami, some international NGOs reported that planning and preparation for housing reconstruction projects took 6-12 months: this included selection of eligible households, plot mapping, spatial planning, obtaining agreements from the community, government and religious leaders, and dealing with appeals. Similarly, in Alto Mayo, Peru, following an earthquake in 1990, a participatory process with communities to plan reconstruction and design houses lasted for six months. ${ }^{12}$ Community and participatory approaches can also be undermined by the pressure to rebuild quickly, particularly where there has been large-scale destruction. ${ }^{13}$

Nevertheless, the 2004 tsunami led to growing interest in more holistic approaches to reconstruction and recovery that address the physical, social and economic conditions required to achieve greater resilience. ${ }^{14}$ Recent research and guidance puts more emphasis on the complexity and evolutionary nature of recovery processes, innovation and adaptation, the involvement and roles of new or different actors, interactions across different levels, and the voices of disaster-affected communities. ${ }^{15}$ Supporting shelter self-recovery is one way for humanitarian agencies to respond and adapt to these perspectives. The international humanitarian shelter sector is increasingly

\footnotetext{
${ }^{10}$ Clinton (2006); Lyons et al. (2010).

${ }^{11}$ Schilderman (2010); Da Silva and Batchelor (2010).

12 Schilderman (1993); Da Silva (2010); Lyons et al. (2010).

13 Da Silva and Batchelor (2010).

${ }^{14}$ Kennedy et al. (2008); Mannakkara and Wilkinson (2013).

15 Few et al. (2014); McManus et al. (2015); Becker and Reusser (2016); Blackman et al. (2017).
} 
moving away from providing housing and towards providing assistance that supports beneficiaries' own shelter self-recovery actions. ${ }^{16}$

\section{Defining self-recovery}

In disaster contexts, the term 'recovery' is broad and open to different approaches and interpretations. It is applied mostly to the physical (reconstruction of houses and infrastructure) and economic (restoring livelihoods and businesses) aspects of disasters, but is also used to refer to post-disaster social and cultural life, physical and mental health, institutional change, power relationships and environmental renewal. Other terms often used synonymously with recovery are: rebuilding, reconstruction, rehabilitation and restoration. In addition, recovery is generally an uneven, long-term process of transition with no clear end point. ${ }^{17}$

The term 'self-recovery' is ambiguous. At first sight it appears self-explanatory and it is popular among humanitarian shelter practitioners, but not always used consistently. It is still not well understood as a reconstruction process. ${ }^{18}$ In fact, it encompasses a wide range of activities and processes. ${ }^{19}$ At one end of this range, it refers to the unassisted self-repair and self-reconstruction which householders engage in, ${ }^{20}$ but self-recovery is so broad and open as a concept that, inevitably, researchers and practitioners have approached it in different ways, focusing on different aspects. From a household's point of view:

Self-recovery can imply self-build, but can also include rebuilding using the local informal building sector. Either way, households rebuild or repair damaged or destroyed homes using their own assets. Assets can be savings, materials (salvaged, donated or owned), social and community assets, local skills and labour. Increasingly, remittances from family members living abroad are an important asset. ${ }^{21}$

Humanitarian programmes described as providing support for shelter self-recovery typically include a combination of: material assistance (including construction materials, tools, salvaging and reuse of debris); financial assistance (cash or vouchers) for the purchase of construction materials, tools or labour; and technical assistance (training, on-site monitoring and the provision of guidance through guidelines/mass communications). ${ }^{22}$

\footnotetext{
16 Schilderman (2004); Davidson et al. (2007); Twigg et al. (2017).

17 Davis and Alexander (2016).

${ }_{18}$ Schofield and Miranda Morel (2017); Harriss et al. (2020).

19 Twigg et al. (2017); Harriss et al. (2020).

20 Parrack et al. (2014).

${ }^{21}$ Parrack et al. (2014: 47).

22 Maynard et al. (2017).
} 
Although post-disaster shelter programmes may describe themselves as supporting 'self-recovery' (or use similar terms signifying beneficiary ownership of the shelter process), this does not necessarily mean that a shelter programme has truly enabled homeowners to recover by themselves. The distinction between 'self-recovery' and similar terms and approaches in post-disaster shelter discourse (e.g. owner-driven, community-based, informal, user-built) is similarly blurred. Community involvement in post-disaster housing projects comprises a variety of possibilities for participation, ranging from providing manual labour to long-range decision-making. ${ }^{23}$ Similarly, self-recovery may comprise different degrees and types of support from family and community members, and local and formal organisations. A decision to support self-recovery does not preclude complementary forms of shelter assistance such as temporary shelters and provision of cash and rental support. ${ }^{24}$

Agencies and researchers have tended to focus on self-recovery through shelter or livelihoods interventions; other self-recovery pathways may exist, but these are not usually examined or understood. ${ }^{25}$ In practice, defining a shelter reconstruction process as one of 'self-recovery' is often based on deciding 'to what degree the process was driven by beneficiaries'. ${ }^{26}$ Although this definitional ambiguity has its drawbacks, 'self-recovery' has value as an umbrella term that enables humanitarians to engage with the broad principle.

The key issue here is the degree to which disaster-affected households are actors and decision-makers regarding the reconstruction of their homes. Where there is no external support, householders are in charge of their 'self-recovery'. Where they are supported by formal shelter programmes, they may have differing degrees of ownership and agency in the reconstruction process. However, the expected outcomes of reconstruction approaches are broadly similar: disaster-affected households live in adequate shelters; they can carry out essential household and livelihood activities; they recover socially and economically; and this contributes to their long-term physical, social, economic and environmental recovery and resilience. ${ }^{27}$

The main point of departure for self-recovery from other participatory and owner-driven approaches is said to be its emphasis on giving much greater choice and agency to disaster-affected households regarding their own recovery pathways. In effect, this recognises that self-recovery is an inevitable process, whether or not external assistance is also provided. ${ }^{28}$ This means shifting from the 'confined choice' that humanitarian and donor agencies tend to offer (e.g. from an approved range of

${ }^{23}$ Davidson et al. (2007); Opdyke et al. (2019).

24 Twigg et al. (2017); Schofield et al. (2019).

${ }^{25}$ Schofield and Miranda Morel (2017).

${ }^{26}$ Harriss et al. (2020: 322).

27 Maynard et al. (2017).

${ }^{28}$ Schofield and Flinn (2018). 
building designs and materials) to giving households much more freedom of choice regarding their priority needs (e.g. choosing between material and technical support for reconstruction, or financial backing to restart livelihood activities). The latter approach also implies greater investment in community mobilisation, knowledge exchange, training and supervision, with agencies putting more emphasis on 'accompaniment' to self-recovery instead of directing reconstruction programmes. ${ }^{29}$

The term 'self-recovery' has appeared almost exclusively in post-disaster shelter discourse, which sees the house or home as the focal point for other forms of recovery (economic/livelihood, social, cultural and psychosocial). In practice, however, the application of 'self-recovery' mainly to the physical and structural aspects of shelter has tended to separate physical reconstruction from other connected and complementary aspects of household and community recovery. ${ }^{30}$

\section{Rationale for self-recovery}

The case for supporting self-recovery is straightforward and pragmatic. The scale of post-disaster shelter need is often beyond the response capacity of humanitarian organisations. ${ }^{31}$ This inevitably leads to growing emphasis on supporting 'self-recovery' and other owner-driven models of shelter and housing reconstruction. ${ }^{32}$ Self-recovery is seen as a means of empowering communities to take charge of their own recovery. It enables cost-effective reconstruction of shelter at scale. Shelter programmes that support households to repair and rebuild their own homes reach a much greater percentage of disaster-affected populations, as per-dwelling costs are considerably lower, especially where provision of building materials and cash is based on an analysis of needs, capacities and local markets, and coupled with strong community engagement as well as technical assistance. While this support does not provide fully engineered buildings, it supports households to build stronger, often larger, houses that are tailored to their needs and resources. Householders learn safer construction techniques and display a strong sense of ownership and pride in the process and the product. ${ }^{33}$

Obtaining reliable data on self-recovery in rapidly changing humanitarian environments is very challenging. There are significant gaps in information about shelter interventions, their coverage and quality; and the information available makes it very difficult to judge how responses contribute to the recovery of households. Nevertheless, there are strong indications that international aid agency support after major disasters

29 Twigg et al. (2017).

${ }^{30}$ Flinn and Echegaray (2016); Newby et al. (undated).

${ }^{31}$ Davis (2011).

${ }^{32}$ Maynard et al. (2017).

${ }^{33}$ Flinn and Echegaray (2016); Flinn et al. (2017); Harriss et al. (2020). 
provides only a small proportion of housing needs. ${ }^{34}$ Inevitably, most houses are repaired or rebuilt by families themselves, using their own assets, which include savings, building materials (salvaged, donated or owned), social and community capital, local skills and labour, and remittances from family members living elsewhere. ${ }^{35}$ Self-recovery in post-disaster shelter 'is not the exception but the norm ... the majority of affected families will inevitably rebuild their homes themselves, using their own resources', which usually leads to adopting 'the same bad building practice that caused their home to be damaged in the first place'. ${ }^{36}$ The clear implication for humanitarian practice is that aid agencies must reposition themselves as advisers and facilitators of shelter assistance, putting more emphasis on communicating and facilitating rebuilding for safety. ${ }^{37}$

\section{Self-recovery's trajectory}

As a term and an approach, 'self-recovery' has taken off rapidly in humanitarian discourse and programming. Its use with regard to shelter and settlements originated relatively recently, in responses to cyclones Sidr (Bangladesh, 2007) and Nargis (Myanmar, 2008), earthquakes in Indonesia (2009) and flooding in Pakistan (2011). The international response to Typhoon Haiyan (Philippines) in 2013 is said to be the first major humanitarian shelter initiative to identify the provision of support for shelter self-recovery as a strategic objective. It has subsequently been a strategic objective in many other humanitarian post-disaster shelter responses. ${ }^{38}$

The 2014 paper by Parrack et al., 'Getting the Message across for Safer Self-recovery in Post-disaster Shelter', ${ }^{39}$ is said to be the first use and discussion of 'self-recovery' in the literature with regard to humanitarian shelter and settlements. ${ }^{40}$ That literature has since grown rapidly. The UK Department for International Development-funded Humanitarian Evidence Programme commissioned an evidence synthesis on self-recovery in 201641 - the most systematic study of the subject to date - and a more recent evidence review has evaluated the state of knowledge about the intersection between supporting shelter self-recovery and building back safer. ${ }^{42}$ Multi-disciplinary field research, which is discussed below, has investigated self-recovery processes in Nepal and the Philippines. ${ }^{43}$

${ }^{34}$ Parrack et al. (2014); Maynard et al. (2017); Miranda Morel (2018).

35 Parrack et al. (2014).

${ }^{36}$ Parrack et al. (2014: 47).

37 Parrack et al. (2014); Harriss et al. (2020).

${ }^{38}$ Maynard et al. (2017); Harriss et al. (2020).

39 Parrack et al. (2014).

${ }^{40}$ Maynard et al. (2017).

${ }^{41}$ Maynard et al. (2017).

${ }^{42}$ Harriss et al. (2020).

43 Twigg et al. (2017); Schofield et al. (2019). 
Self-recovery has been the focus of in-country workshops in several countries and the subject of presentations and discussions at international conferences. ${ }^{44}$ These are generally believed to have been influential in raising the profile of the topic, improving knowledge and understanding, and expanding the scope of enquiries and discussions. The 'Promoting Safer Building' initiative (2016-17, discussed below) rapidly attracted a large informal network of people from humanitarian and development organisations, grassroots organisations, government and policy institutions, academic and scientific institutions, and the private sector, who engaged with the project in one way or another. ${ }^{45}$

In 2017, self-recovery received global institutional backing when it was adopted as a working group of the Inter-Agency Standing Committee (IASC) Global Shelter Cluster as part of its 2018-2022 Strategy. ${ }^{46}$ The issue was also identified as a priority research topic for the humanitarian shelter and settlements sector in a recent Delphi survey of expert informants. ${ }^{47}$

Some of the impetus for this interest in self-recovery may have come from the 2016 Istanbul World Humanitarian Summit's emphasis on supporting local actors in disaster response and recovery, with the UN Secretary General stating that humanitarian action should be 'as local as possible, as international as necessary'. The so-called 'grand bargain' launched during the summit and the 'localisation' agenda that followed have seen international donor and operational agencies committing to greater support for local humanitarian action. ${ }^{48}$

${ }^{44}$ Notably presentations at several international events held in 2017: biennial UN Global Forum on Disaster Risk Reduction, Cancun, Mexico; 3rd International Urban Sustainability and Resilience Conference, London, UK; 8th i-Rec Conference, Toronto, Canada; Global Facility for Disaster Risk Reduction, 3rd World Reconstruction Conference, Brussels, Belgium; international conference on 'Promoting safer building and supporting self-recovery', London, UK.

45 CARE International UK (2017).

${ }^{46}$ Global Shelter Cluster (2018). The Inter-Agency Standing Committee (IASC) is an inter-agency forum for coordination, policy development and decision-making involving key UN and non-UN humanitarian partners. The Global Shelter Cluster (GSC) is an IASC coordination mechanism that enables better co-ordination among all shelter actors, including local and national governments. The GSC is a public platform with 44 partners, co-chaired by the International Federation of Red Cross and Red Crescent Societies (IFRC) and the United Nations High Commissioner for Refugees (UNHCR).

${ }^{47}$ Opdyke et al. (2018).

48 Barbelet (2018). 


\section{Understanding self-recovery through research}

Humanitarian action is the opposite of science. Scientists make conclusions when they have complete data. We make conclusions and decisions without complete data. ${ }^{49}$ (Speaker from international humanitarian agency at self-recovery conference, London, July 2017)

As self-recovery began to attract more interest from humanitarians, it became clear that there were limitations in agencies' knowledge and understanding of it. They rely heavily on evaluations and reports on agency interventions, but knew little about self-recovery processes outside this scope. Empirical research was needed. Coincidentally, research funding opportunities became available through the UK Government's Global Challenges Research Fund, set up in 2015 to support cutting-edge research addressing challenges in developing countries. ${ }^{50}$ Grants from the Natural Environment Research Council (2016-17) and the British Academy (2018-19) supported field studies of self-recovery after disasters in Nepal (Gorkha earthquake, 2015) and Philippines (typhoons Haiyan, 2013, and Haima, 2016). ${ }^{51}$ The first study, 'Promoting safer building - using science, technology, communication and humanitarian practice to support family and community self-recovery', looked at self-recovery in rural and some peri-urban contexts in the two countries; the second focused on urban locations. ${ }^{52}$ These projects were multi-disciplinary collaborations of social scientists, geoscientists, structural engineers and humanitarian practitioners. They sought to understand how individual households and communities recover from disasters, what 'recovery' consists of for disaster-affected people, the strategies adopted by households and communities to self-recover, the roles and influence of formal organisations on the self-recovery process, and interventions or conditions that support safer self-recovery.

Researchers investigated household self-recovery trajectories and the wide range of technical, environmental, institutional and socio-economic factors that influenced them, as well as looking at how safer construction practices could be adopted and implemented more effectively. The field research combined methods used in qualitative social science (transect walks, focus groups, semi-structured interviews, timeline mapping), structural engineering and architecture (building surveys), and geosciences (geological and geomorphological surveys). Meetings were also held with representatives of key institutions at national level. External validation was provided by expert workshops in Manila and

\footnotetext{
${ }^{49}$ CARE International UK (2017: 12).

${ }^{50}$ www.ukri.org/research/global-challenges-research-fund/

51 'Promoting safer building - using science, technology, communication and humanitarian practice to support family and community self-recovery' (2016-17) funded by the UK Natural Environment Research Council (ref. NE/P016200/1) and the CARE UK Investment Fund; 'Safer self-recovery: promoting resilient urban reconstruction after disasters' (2018-19) funded by the British Academy (ref. CI170172).

52 Twigg et al. (2017); Schofield et al. (2019).
} 
Kathmandu to discuss initial research findings with key stakeholders, including local, national and international humanitarian organisations and donors. Additional feedback came from the project's advisory group, which held regular meetings, and from an international conference of researchers and practitioners in London in July $2017 .{ }^{53}$

The field research methodology was novel and experimental. Despite a common research topic and a genuine commitment to multi-disciplinary working, not all of the team members were comfortable with the approach, and some implicit assumptions and biases remained largely hidden until the writing up of the data. This was particularly true for the first project; and planning for the second project revealed a clear desire among some researchers to draw back into their specialist areas of expertise. Nevertheless, the field research was pivotal in expanding understanding of shelter self-recovery and revealing its complexity, providing new insights into household decision-making and its consequences for future resilience. This evidence also brought attention to the issue, created momentum and supported further growth of a community of practice, paving the way for more empirical research.

Disaster-affected households face many significant environmental, institutional, financial and social challenges: obtaining material and financial resources for rebuilding homes and livelihoods; deciding when, how and where to rebuild; acquiring skills or technical guidance; rebuilding in altered or disrupted physical environments; negotiating national and local bureaucracies, rules and regulations; ensuring family security and safety; and coping with the psychological consequences of disaster. The degree of choice open to households is influenced not only by the extent of their disaster losses, but also by: poverty level; social status; connections (social and political); housing, land and property rights and tenure systems; the availability and usefulness of scientific and technical knowledge and skills; and access to markets and financial and material assistance. Self-recovery was revealed as a multi-faceted, dynamic process. Households are pragmatic and adaptive: their needs, priorities and opportunities shift frequently over time and according to changing circumstances (e.g. the arrival of monsoon rains or availability of different forms of assistance) and as a consequence of the policies and interventions of different external actors. ${ }^{54}$ Moreover, shelter programming needs to be very context-specific, since building typologies and social structures can vary widely within a country. ${ }^{55}$

\footnotetext{
53 'Promoting safer building and self-recovery in the Philippines' (2017); 'Promoting safer building and selfrecovery in Nepal' (2017); 'Promoting safer building and supporting self-recovery: report of Promoting Safer Building Multidisciplinary Conference, Royal Geographical Society, London, 13 July 2017'.

54 Twigg et al. (2017); Schofield et al. (2019); Sargeant et al. (2020).

55 Flinn and Echegaray (2016).
} 


\section{Building back safer}

The safety argument has been central to self-recovery discourse. Humanitarian agencies' support to self-recovery has focused on ensuring that householders do not simply repeat unsafe designs and building practices. It is axiomatic within the humanitarian shelter sector that making houses safer should be a primary goal of reconstruction programming: one of the 10 'Key Propositions for Building Back Better' in the Clinton report on the 2004 tsunami is that 'Good recovery must leave communities safer by reducing risks and building resilience' ${ }^{56}$ However, the widely used terms 'safe' and 'safer' are relative and imprecise. They need to be defined - and where possible, measured - in relation to different construction techniques and technologies. Humanitarian responders and householders may have different safety priorities: the former focusing on safety from environmental hazards; the latter more aware of other forms of safety, such as privacy and security from crime and violence. ${ }^{57}$

Rebuilding depends on the availability of finance, technical skills and support, and appropriate construction materials. Reconstruction programmes facing time and resource limitations invariably have to weigh up housing quality against speed of delivery and quantity. Households and agencies face difficult operational decisions about what level of safety is desirable and achievable, and what is good enough or fit for purpose. Several factors make it difficult for householders to adopt safer construction: these include lack of understanding of safer building methods, the higher cost of hazard-resistant construction techniques, the amount of technical and financial support available, and the demands of local building codes. ${ }^{58}$

The choice-based approach that self-recovery implies also creates ethical questions that are often overlooked in the literature on shelter and disasters. It transfers some ownership of risk from relief agencies to households. Whilst NGOs and other technical support organisations can give good advice and encourage safe practice in construction and site choices, self-recovery means that decision-making rests with the families concerned. Humanitarian agencies have to make trade-offs between achieving high levels of safety in a smaller number of houses or reaching a much larger number of houses with a lesser degree of safety. Building back safer may not be the top priority for families - restoring livelihoods is often the most immediate need - and assisting agencies may have to focus on ensuring that households make well-informed decisions. ${ }^{59}$

\footnotetext{
${ }^{56}$ Clinton (2006: 22-3).

${ }^{57}$ Flinn (2020).

${ }^{58}$ Harriss et al. (2020).

59 Flinn (2019); Twigg et al. (2017); Parrack et al. (2014).
} 


\section{Expanding the scope of self-recovery}

The two field research projects and the events, publications and outputs that they generated have widened the scope of enquiry beyond the effectiveness of humanitarian assistance. Self-recovery appears to have been a catalyst for a more holistic perspective on recovery and reconstruction, taken up by research team members or independently by other researchers. Additional UK research council funding to translate research into practice has supported a new collaborative project to develop best-practice guidance for supporting self-recovery processes, drawing on the the research projects and operational experiences. ${ }^{60}$ This has led, for example, to work on how dynamic, multi-hazard environments affect household and community self-recovery. Here, researchers have used land systems mapping to understand the physical aspects of the landscape and implications for safer rebuilding. Following on from this, a workshop was held for representatives from the international geoscience and humanitarian communities to share experiences of cross-disciplinary working, explore how geoscience could be a resource in humanitarian shelter practice, and start a conversation on collaboration. ${ }^{61}$

Knowledge exchange regarding rebuilding houses, and drivers and barriers relating to adoption of hazard-resistant construction knowledge by disaster-affected households, have also been investigated. ${ }^{62}$ A review commissioned by InterAction (a USA-based coalition of international NGOs) has considered the impacts of shelter and settlements assistance on health (physical and mental), livelihoods, hazard risk, social cohesion and gender. ${ }^{63}$

Shelter and health has emerged as an important area of investigation, looking beyond environmental hazards to a wider range of risk factors (including indoor air pollution, overcrowding, thermal extremes, poor sanitation and unsafe water) and considering how humanitarian shelter interventions might address these. ${ }^{64}$

\section{Conclusion}

The rapid adoption of self-recovery ideas and practices is remarkable. This could be seen as the latest stage in the decades-long evolution of humanitarian agencies' approaches to shelter reconstruction, building on previous participatory and

${ }^{60}$ Self-recovery housing for development: scaling up crisis preparedness and humanitarian shelter response. Engineering and Physical Sciences Research Council EP/T015160/1.

${ }^{61}$ Simons and Sargeant (2020).

${ }^{62}$ Hendriks (2017); Hendriks and Stokmans (2020).

${ }^{63}$ Kelling (2020).

${ }^{64}$ A recent one-day webinar on this subject attracted more than 100 academics and practitioners from around the world: Webb et al. (2020). 
owner-driven approaches. However, many experienced shelter professionals regard it as more innovative. It exemplifies adaptive capacity and practice, but can even be seen as transformative, since transformation implies elasticity, diversity, innovation (of processes, methods, institutional relationships, technologies) and empowerment. ${ }^{65}$ The relative open-endedness of the self-recovery idea makes it inclusive and allows for variations in approach.

The enabling environment has been favourable for introducing self-recoveryindeed, self-recovery proponents seem to have been pushing at an open door. The international humanitarian shelter sector encourages innovation. Its culture is reflective and often highly self-critical, with a strong desire to learn and improve. Its performance, both sector-wide and in individual disasters, is regularly reviewed. Since 2007, the Global Shelter Cluster has published seven Shelter Projects volumes: compendiums of experiences of shelter response and reconstruction in recent disasters worldwide, looking at strengths, weaknesses and lessons learned. The 2018 State of Humanitarian Shelter and Settlements report, also published by the Global Shelter Cluster, was a wide-ranging review of the sector's work and impact, identifying achievements and challenges.$^{66}$ Regular meetings of shelter practitioners and academics - in particular, the Shelter and Settlements Working Group in the USA, hosted by InterAction, and the UK Shelter Forum ${ }^{67}$ - are open events to discuss new ideas and approaches, and strengthen consensus. This is a strong, dynamic community of practice. The sector seeks to widen its scope and embrace new thinking and practice in order to achieve greater impact. For example, recent years have seen growing interest in area-based and settlements approaches, which place shelter reconstruction in its wider spatial and locational context. ${ }^{68}$

Self-recovery is not a universal solution to the humanitarian shelter problem and there are some significant gaps in the way it is perceived and applied. For instance, it has yet to link to the wide, long-running academic discourse on informality and emergence in disaster contexts. Spontaneous responses by self-organising, emergent voluntary groups and individuals, drawing on existing social capital and networks, are a common feature of disasters, and an important resource and capacity for emergency response, although they are usually overlooked by formal aid organisations. ${ }^{69}$ This still receives very little attention from the shelter sector.

Another major gap is that self-recovery conversations, thinking and implementation are led largely by international aid agencies. Other actors, particularly national

${ }^{65}$ Twigg et al. 2020.

${ }^{66} \mathrm{http}: / /$ shelterprojects.org/.

${ }^{67}$ www.interaction.org/working-groups/; www.shelterforum.info/category/united-kingdom/

${ }_{68}^{6}$ Parker and Maynard (2015); Setchell (2018).

${ }^{69}$ Stallings and Quarantelli (1985); Drabek and McEntire (2003); Whittaker et al. (2015); Twigg and Mosel (2017). 
and local governments, are far less visible in public discourse on the subject, and sometimes appear to be seen more as targets for influencing than as partners.

Finally, it should be noted that post-disaster recovery is a complex, non-linear, dynamic process which often takes place in rapidly changing conditions. Endpoints cannot easily be defined, making it difficult to measure success. ${ }^{70}$ The very term 'recovery' is open to a variety of interpretations, depending on different knowledges, experiences and perspectives. It implies a process of improvement and return to some kind of normality that many disaster-affected people may not be able to obtain. This overlooks the fact that post-disaster contexts are likely to be very different from pre-disaster conditions, creating a 'new normal' with different demands and priorities. ${ }^{71}$ It may be more realistic and constructive to think in terms of post-disaster 'transitions', encompassing a range of options and strategies for managing greatly altered environments over extended periods of time. Self-recovery practices will grow and adapt to such contexts. Further, longitudinal, studies could inform our understanding of such processes and the role that self-recovery plays.

\section{Acknowledgements}

The author thanks the Natural Environment Research Council, the British Academy and the CARE UK Investment Fund for funding the research projects which this article draws upon; CARE International UK, CARE Nepal and CARE Philippines for logistical and other support in the field, and organising workshops and conferences; research team members and administrators from CARE, Overseas Development Institute, British Geological Survey, Loughborough University, University College London, and in-country counterparts; and participants in national and international workshops and roundtables. The author takes responsibility for the views expressed in the article.

\section{References}

Ashdown, P. (2011), Humanitarian Emergency Response Review (London, Department for International Development).

Barbelet, V. (2018), As Local as Possible, as International as Necessary: Understanding Capacity and Complementarity in Humanitarian Action (London, Overseas Development Institute).

Becker, S. \& Reusser, R. (2016), 'Disasters as Opportunities for Social Change: Using the Multi-level Perspective to Consider the Barriers to Disaster-related Transitions', International Journal of Disaster Risk Reduction, 18: 75-88.

70 Johnson and Hayashi (2012); Blackman et al. (2017).

${ }^{71}$ Tierney \& Oliver-Smith (2012). 
Blackman, D., Nakanishi, H. \& Benson, A. (2017), 'Disaster Resilience as a Complex Problem: Why Linearity is not Applicable for Long-term Recovery', Technology Forecasting and Social Change, 121: 89-98.

CARE International UK (2017), 'Promoting Safer Building and Supporting Self-recovery: Report of Promoting Safer Building Multidisciplinary Conference, Royal Geographical Society, London, 13 July 2017'.

Clinton, W.J. (2006), Key Propositions for Building Back Better (New York, Office of the United Nations Secretary-General's Envoy for Disaster Recovery).

Da Silva, J. (2010), Lessons from Aceh: Key Considerations in Post-disaster Reconstruction (Rugby, Practical Action Publishing).

Da Silva, J. \& Batchelor, V. (2010), 'Indonesia: Understanding Agency Policy in a National Context', in M. Lyons, T. Schilderman \& C. Boano (eds), Building Back Better: Delivering People-centred Housing Reconstruction at Scale (Rugby, Practical Action Publishing), 135-64.

Davidson, C., Johnson, C., Lizzaralde, G., Dikmen, N. \& Sliwinski, A. (2007), 'Truths and Myths about Community Participation in Post-disaster Housing Projects', Habitat International, 31: 100-15.

Davis, I. (1978), Shelter after Disaster (Oxford, Oxford Polytechnic Press).

Davis, I. \& Alexander, D. (2016), Recovery from Disaster (Abingdon, Routledge).

Davis, I., Thompson, P. \& Krimgold, F. (eds) (2015), Shelter after Disaster (Geneva, International Federation of Red Cross and Red Crescent Societies and United Nations Office for the Coordination of Humanitarian Affairs).

Davis, I., Cuny, F., Thompson, P., Krimgold, F. \& Fernandez, A. (1982), Shelter after Disaster: Guidelines for Assistance (Geneva, Office of the United Nations Disaster Relief Co-ordinator).

Drabek, T. \& McEntire, D. (2003), 'Emergent Phenomena and the Sociology of Disaster: Lessons, Trends and Opportunities from the Research Literature', Disaster Prevention and Management, 12: 97-112.

Few, R., McAvoy, D., Tarazona, M. \& Walden, V.M. (2014), Contribution to Change: An Approach to Evaluating the Role of Intervention in Disaster Recovery (Rugby, Practical Action Publishing).

Flinn, B. (2019), Humanitarian Shelter and the Ethics of Self-recovery: A Discussion Paper (London, CARE International UK).

Flinn, B. (2020), 'Defining "Better" Better: Why Building Back Better Means More than Structural Safety', Journal of Humanitarian Affairs, 2: 60-8.

Flinn, B. \& Echegaray, M. (2016), Stories of Recovery: CARE Philippines Post Haiyan/Yolanda Shelter Response (London and Manila, CARE International UK and CARE Philippines).

Flinn, B., Schofield, H. \& Miranda Morel, L. (2017), 'The Case for Self-recovery', Forced Migration Review, 55: 12-14.

Harriss, L., Parrack, C. \& Jordan, Z. (2020), 'Building Safety in Humanitarian Programmes that Support Post-disaster Shelter Self-recovery: An Evidence Review’, Disasters, 44: 307-35.

Hendriks, E., Basso, M., Sposini, D., van Ewijk, L. \& Jurkowska, H. (2017), 'Self-built Housing as an Alternative for Post-disaster Recovery', paper delivered to No-cost Housing Conference, ETH Zürich.

Hendriks, E. \& Stokmans, M. (2020), 'Drivers and Barriers for the Adoption of Hazard-resistant Construction Knowledge in Nepal: Applying the Motivation, Ability, Opportunity (MAO) Theory', International Journal of Disaster Risk Reduction, 51, 101778.

Johnson, L. \& Hayashi, H. (2012), 'Synthesis Efforts in Disaster Recovery Research', International Journal of Mass Emergencies and Disasters, 30: 212-38.

Kelling, F. (2020), The Wider Impacts of Humanitarian Shelter and Settlement Assistance: Key Findings Report (Washington, DC, InterAction).

Kennedy, J., Ashmore, J., Babister, E. \& Kelman, I. (2008), 'The Meaning of "Build Back Better": Evidence from Post-tsunami Aceh and Sri Lanka', Journal of Contingencies and Crisis Management, 16: $24-36$. 
Lyons, M., Schilderman, T. \& Boano, C. (eds) (2010), Building Back Better: Delivering People-centred Housing Reconstruction at Scale (Rugby, Practical Action Publishing).

Mannakkara, S. \& Wilkinson, S. (2013), 'Build Back Better Principles for Post-disaster Structural Improvements', Structural Survey, 31: 314-27.

Maynard, V., Parker, E. \& Twigg, J. (2017), The Effectiveness and Efficiency of Interventions Supporting Shelter Self-recovery Following Humanitarian Crises: An Evidence Synthesis (Oxford, Oxfam GB).

McManus, R., Johnston, D. \& Glavovic, B. (2015), 'Contested Meanings of Recovery: A Critical Exploration of the Canterbury Earthquakes - Voices from the Social Sciences', Kotuitui: New Zealand Journal of Social Sciences Online, 10: 69-71.

Miranda Morel, L. (2018), 'Shelter Assistance: Gaps in the Evidence' (London, CARE International UK, discussion paper).

Newby, T., Montejo, M. \& Nouraini, S. (undated), CARE Philippines Typhoon Haiyan Shelter Recovery Project Evaluation (London, CARE International UK).

Opdyke, A., Javernick-Will, A. \& Goldwyn, B. (2018), 'Defining a Humanitarian Shelter and Settlements Research Agenda', presentation to UK Shelter Forum 2018.

Opdyke, A., Javernick-Will, A. \& Koschmann, M. (2019), 'Assessing the Impact of Household Participation on Satisfaction and Safe Design in Humanitarian Shelter Projects', Disasters, 43: 926-53.

Parker, E. \& Maynard, V. (2015), Humanitarian Response to Urban Crises: A Review of Area-based Approaches (London, International Institute for Environment and Development).

Parrack, C., Flinn, B. \& Passey, M. (2014), 'Getting the Message across for Safer Self-recovery in Postdisaster Shelter', Open House International, 39: 47-58.

Sargeant, S., Finlayson, A., Dijkstra, T., Flinn, B., Schofield, H., Miranda Morel, L., Twigg, J., Lovell, E., Stephenson, V. \& Adhikari, B.R. (2020), 'The Influence of the Physical Environment on Selfrecovery after Disasters in Nepal and the Philippines', International Journal of Disaster Risk Reduction, 50, 101673.

Schilderman, T. (1993), 'Disasters and Development: A Case Study from Peru', Journal of International Development, 5: 415-23.

Schilderman, T. (2004), 'Adapting Traditional Shelter for Disaster Mitigation and Reconstruction: Experiences with Community-based Approaches', Building Research \& Information, 32: 414-26.

Schilderman, T. (2010), 'Putting People at the Centre of Reconstruction', in M. Lyons, T. Schilderman \& C. Boano (eds), Building Back Better: Delivering People-centred Housing Reconstruction at Scale (Rugby, Practical Action Publishing), 7-37.

Schofield, H. \& Flinn, B. (2018), 'People First: Agency, Choice and Empowerment in Support to Selfrecovery', in D. Sanderson \& A. Sharma (eds), The State of Humanitarian Shelter and Settlements (Geneva, International Federation of Red Cross and Red Crescent Societies and United Nations Office for the Coordination of Humanitarian Affairs), 29-33.

Schofield, H. \& Miranda Morel, L. (2017), 'Whose Recovery? Power, Roles and Ownership in Humanitarian Shelter Assistance', Humanitarian Exchange, 69: 29-30.

Schofield, H., Lovell, E., Flinn, B. \& Twigg, J. (2019), 'Barriers to Urban Shelter Self-recovery in Philippines and Nepal: Lessons for Humanitarian Policy and Practice', Journal of the British Academy, 7(s2): 83-109.

Setchell, C. (2018), 'The Emerging Importance of the Settlement Approach', in State of Humanitarian Shelter and Settlements 2018 (Geneva, Global Shelter Cluster), 114-19.

Sharma, A. (2018), 'Supporting Locally-driven Shelter Responses', in State of Humanitarian Shelter and Settlements 2018 (Geneva, Global Shelter Cluster), 19-24.

Simons, B. \& Sargeant, S. (eds), Exploring linkages between humanitarian science and humanitarian shelter: workshop report (Nottingham, British Geological Survey).

Stallings, R. \& Quarantelli, E. (1985), 'Emergent Citizen Groups and Emergency Management', Public Administration Review, 45: 93-100. 
Tierney, K. \& Oliver-Smith, A. (2012), 'Social Dimensions of Disaster Recovery', International Journal of Mass Emergencies and Disasters, 30: 123-46.

Twigg, J. \& Mosel, I. (2017), 'Emergent Groups and Spontaneous Volunteers in Urban Disaster Response', Environment \& Urbanization, 29: 443-58.

Twigg, J., Lovell, E., Schofield, H., Miranda Morel, L., Flinn, B., Sargeant, S., Finlayson, A., Dijkstra, T., Stephenson, V., Albuerne, A., Rossetto, T. \& D’Ayala, D. (2017), Self-recovery from Disasters: An Interdisciplinary Perspective (London, Overseas Development Institute).

Twigg, J., Pilkinton, J., Carnaby, E., Sterrett, C.\& Hogan, L. (2020), Accountable Governance and Resilient Development: Thinking and Acting for Transformative Change (Carlton, Oxfam Australia).

Webb, S., Weinstein Sheffield, E. \& Flinn, B. (eds) (2020), Towards Healthier Homes in Humanitarian Settings (Oxford, Centre for Development and Emergency Practice, Oxford Brookes University and CARE International UK).

Whittaker, J., McLennan, B. \& Handmer, J. (2015), 'A Review of Informal Volunteerism in Emergencies and Disasters: Definitions, Opportunities and Challenges', International Journal of Disaster Risk Reduction, 13: 358-68.

To cite the article: John Twigg (2021), 'The evolution of shelter "self-recovery": adapting thinking and practice for post-disaster resilience', Journal of the British Academy, 9(s8): 5-22.

DOI https://doi.org/10.5871/jba/009s8.005

Journal of the British Academy (ISSN 2052-7217) is published by

The British Academy, 10-11 Carlton House Terrace, London, SW1Y 5AH

www.thebritishacademy.ac.uk 